\title{
Identity and Safety of a Novel Aurantiochytrium sp. for Terrestrial Heterotrophic Docosahexaenoic Acid Production
}

\author{
Andrew Norman William Bell ${ }^{1}$, Colm Anthony Moran² \\ ${ }^{1}$ Regulatory Affairs Department, Alltech Ireland, Dunboyne, Ireland \\ ${ }^{2}$ Regulatory Affairs Department, Alltech SARL, Vire, France \\ Email: cmoran@alltech.com
}

How to cite this paper: Bell, A.N.W. and Moran, C.A. (2020) Identity and Safety of a Novel Aurantiochytrium sp. for Terrestrial Heterotrophic Docosahexaenoic Acid Production. Advances in Bioscience and Biotechnology, 11, 489-509. https://doi.org/10.4236/abb.2020.1112033

Received: November 17, 2020

Accepted: December 28, 2020

Published: December 31, 2020

Copyright $\odot 2020$ by author(s) and Scientific Research Publishing Inc. This work is licensed under the Creative Commons Attribution International License (CC BY 4.0).

http://creativecommons.org/licenses/by/4.0/

\section{(c) (i) Open Access}

\begin{abstract}
The objective of the studies in this paper was to expand on the published toxicological assessment of Aurantiochytrium limacinum (AURA) with further strain characterization and to investigate the potential for the biomass or extracted oil to have antimicrobial properties or undesirable substances. AURA is being investigated as a novel source of the omega-3 long-chain polyunsaturated fatty acid docosahexaenoic acid (DHA) for enriching foods of animal origin by means of feed supplementation. In the first studies, we provided the $18 \mathrm{~S}$ rRNA identification of the novel marine isolated thraustochytrid, established the nutritional composition of AURA biomass for application as a food or feed ingredient including proximate analysis and fatty acid profiling, and confirmed the DHA production potential of the strain. We determined through minimum inhibitory concentration (MIC) analysis that the unextracted AURA biomass was safe, showing no antimicrobial influence and no evidence of any deleterious effects of this product or its extracts at concentrations up to $1 \% \mathrm{w} / \mathrm{w}$ on the reference human intestinal bacteria tested. This would indicate that AURA should not stimulate selective pressure on the commensal microbiota and is therefore unlikely to aid development of antimicrobial resistance and the concomitant harm to humans and animals. Further analysis revealed that the AURA biomass produced through industrial heterotrophic fermentation was free from undesirables; toxic marine microalgal metabolites, heavy metals, pesticides, microbial contaminants, and mycotoxins. Including heterotrophically-grown AURA in food or feed, up to $1 \%$ $\mathrm{w} / \mathrm{w}$, is a safe and environmentally beneficial strategy for DHA supplementation.
\end{abstract}

\section{Keywords}

Thraustochytrid, Docosahexaenoic Acid, Fatty Acids, Aurantiochytrium 
limacinum, Minimum Inhibitory Concentration, Antimicrobial Resistance

\section{Introduction}

The challenges of feeding a growing global population continue to be met by the food industry worldwide. However, it is true that changing environmental considerations must influence the origin of our food sources. Wild-caught seafood is the primary source of dietary long chain polyunsaturated fatty acids in the human diet through the direct consumption of seafood, nutritional supplements or through inclusion of fish products into the diets of other aquatic or terrestrial animals [1]. Supplementation of ruminant diets with fish oil has been shown to promote the prevalence of unsaturated fatty acids in meat and dairy products [2] [3], a fact that may have implications for human health where a reduction in saturated fat consumption and an accompanying increase in unsaturated fats can reduce the incidence of heart disease and other associated conditions [4] [5]. Harvesting from the marine environment to feed aquaculture and terrestrial agriculture is unlikely to be sustainable in the long term, and appropriate alternatives must be sought [6] [7]. When considering the source of unsaturated fatty acids, there are a range of safety factors to consider. Bioaccumulation of heavy metals, persistent organic contaminants and toxins derived from marine microalgae can result in high levels of contaminants in fish oils owing to the low metabolic capacity of fish [8] [9]. Reduction or removal of these contaminants is vital to prevent introduction into the food chain as their toxicity can offset the benefits of inclusion in food and feed to humans and animals alike [10].

Oils derived from terrestrial heterotrophic fermentation using marine sourced protists have a number of proven advantages over fish oil; terrestrial production is scalable, it is more sustainable owing to growth on simple carbon sources, there is no direct impact on the marine environment, and it can produce a more consistent and cost-effective product [11] [12]. Frequently referred to as an algae or marine microalgae, Aurantiochytrium limacinum (AURA) is actually a member of the Stramenopile group, recently described as athraustochytrid or protist, exhibiting non-photosynthetic fungal physiological traits [13]. This oleaginous unicellular organism has proven safe through recent toxicological and genotoxicity testing [14] and useful for the production of docosahexaenoic acid (DHA) rich biomass for dietary application in food-producing animals. Such dietary supplementation has demonstrated efficacy in elevating levels of DHA and EPA (eicosapentaenoic acid) as well as other omega-3 fatty acids in milk [15], meat [16] [17] [18] and eggs [19] [20], a valuable means of supplementing the human diet.

From a safety perspective it is notable that primary desirable components of fish/algal oil supplements (DHA for example) have shown some antimicrobial activity [4]. There is often an overlap between compounds regarded as toxins and those seen as antimicrobials. Secondary metabolites (SM) derived from cel- 
lular processes can give an organism an advantage against its competitors, penicillin is an example of such a compound [21]. Marine microalgae are known producers of bioactive SMs such as Saxitoxin, Domoic acid and a variety of polyketides [9] [22]. Polyketides are SMs associated with fatty acid synthesis and are often of clinical importance with roles in immunosuppression, cancer treatment and as antimicrobial agents [23] [24] [25]. In the context of mitigating risks associated with the introduction of a novel feed material, it is prudent to determine the overall safety of the material and assess the potential for antimicrobial activity, or for antimicrobial residues to be suspended within the material.

The goal with this set of studies was to provide complementary information to our recent safety assessment of AURA [14]; including more detailed information on the identity and product composition; safety information in relation to contaminants and undesirables: mycotoxins, heavy metals and pesticides; a hazard characterization confirming that unextracted Aurantiochytrium, its biomass and metabolites, are safe with respect to antimicrobial resistance to a reasonable certainty of no harm to humans; and finally test whether residues or metabolites from the unextracted Aurantiochytrium biomass, or extracted oil, could result in putative residues in edible tissues that may affect human intestinal flora. Our studies followed the United States Food and Drug Administration Center for Veterinary Medicine (CVM) Guidance for Industry (GFI) \#3 “General Principles for Evaluating the Safety of Compounds Used in Food-Producing Animals" [26] for the residue chemistry portion; GFI \#152, "Evaluating the Safety of Antimicrobial New Animal Drugs With Regard to Their Microbiological Effects on Bacteria of Human Health Concern" [27] for antimicrobial resistance testing, and GFI \#159 "Studies to Evaluate the Safety of Residues of Veterinary Drugs in Human Food: General Approach to Establish a Microbiological ADP” [28] for guidance on test procedures to interrogate potential impacts of AURA on the human intestinal microflora.

\section{Materials and Methods}

\subsection{Biochemical Profiling}

A heterotrophically grown, unextracted AURA biomass powder (CCAP 4087/2) was provided to Minnesota Valley Testing Laboratory (MVTL, New Ulm, MN, USA) by Alltech Inc. (Nicholasville, KY, USA). The analytical composition of the biomass product was determined in compliance with current Good Laboratory Practices (GLP) guidelines (21 CFR part 58): crude protein (AOAC 990.03 [29]), crude fat (AOAC 954.02 [30]), Fatty acid composition (AOAC 996.06 [31]), moisture (AOAC 930.15 [32]), and ash (AOAC 942.05 [33]).

\subsection{S rRNA Culture Identification}

A purified monoculture of metabolically active culture was supplied to the Culture Collection of Algae at the University of Texas (Austin, Texas, USA) by All- 
tech Inc. (Nicholasville, KY, USA) for identification and characterisation within the College of Natural Sciences (University of Texas at Austin, College of Natural Sciences, Austin, TX, USA). Colonies were isolated and multiplied in Medium- $\mathrm{H}$ for the following analyses: $18 \mathrm{~S}$ rRNA identification, Minimum inhibitory concentration and polyketide analysis (Sections 2.3, 2.4 and 2.5). DNA was extracted from the micro-organism using a modification of the JGI protocol for CTAB mediated bacterial genomic DNA isolation (outlined in [34]) and PCR amplification was performed with universal $18 \mathrm{~S}$ primer sets. Reading produced a partial $18 \mathrm{~S}$ sequence which was compared to the NCBI BLAST database to determine sequence similarity.

\subsection{Minimum Inhibitory Concentration (Disc Diffusion)}

\section{Compounds, extraction and bacterial strains}

Whole cells were selected during mid-exponential phase and concentrated through centrifugation. The growth-medium supernatant was separated and stored for later solid-phase extraction while the remaining cells were prepared for solvent extraction. Solvent extraction involved repeated suspension in cold acetone followed by centrifugation and decantation to remove pigmentation. Remaining cellular mass was then extracted with four methanol washes before being homogenized in $80 \%$ 1-propanol/ water solution. Homogenate underwent centrifugation to separate cellular material and the subsequent supernatant joined the methanol extracts. This homogenization process was repeated a second time with the $80 \% 1$-propanol/water solution. The extract mixture was evaporated to remove solvent and resuspended in $2 \mathrm{ml}$ of water. $2 \mathrm{ml}$ of ethyl acetate was used to de-fat this mixture; the aqueous phase was de-fatted a total of four times and again dried. In order to elute the desired analytes, cellular extract was suspended in $10 \mathrm{ml}$ of $25 \% 1$-propanol/water and passed through a chromatography cartridge, washed with 45\% 1-propanol/water solution, eluted in $80 \%$ 1-propanol/water solution and dried. $30 \mathrm{ml}$ of growth-medium supernatant was mixed with $10 \mathrm{ml}$ of 25\% 1-propanol/water solution and the same solid-phase extraction process was followed. The resulting dried cellular extract and supernatants were suspended in 5\% methanol/water solution for use in MIC analysis [35]. DH5a E. coli culture was used as the reference culture for the MIC analyses.

\section{Minimum inhibitory concentration determination}

The experiment was carried out in accordance with CLSI M02-A12 guidelines using the Disc diffusion method [36]. Whole cells or extracts were tested as follows.

Nine discs were placed onto sterile LB agar plates to accommodate the cell extracts. Eight discs were placed around the plate and one disc was applied to the center of the plate. The central disc received a dose of 5\% Methanol solution as a negative control. Four discs received concentrations of the test solutions (Table 1) while the remaining four discs had positive controls applied. For analysis with 
Table 1. Disc diffusion test and positive control concentrations.

\begin{tabular}{ccc}
\hline $\begin{array}{c}\text { Test/positive control } \\
\text { solution }\end{array}$ & $\begin{array}{c}\text { Conc. Applied } \\
\text { (Replicate 1) }\end{array}$ & $\begin{array}{c}\text { Conc. Applied } \\
\text { (Replicate 2) }\end{array}$ \\
\hline Cellular extract & $10 \mu \mathrm{g}$ and $20 \mu \mathrm{g}$ & $40 \mu \mathrm{g}$ and $80 \mu \mathrm{g}$ \\
Supernatant extract & $10 \mu \mathrm{g}$ and $20 \mu \mathrm{g}$ & $40 \mu \mathrm{g}$ and $80 \mu \mathrm{g}$ \\
Ampicillin & $100 \mu \mathrm{g}$ and $200 \mu \mathrm{g}$ & $1 \mathrm{mg}$ and $2 \mathrm{mg}$ \\
Streptomycin & $100 \mathrm{ng}$ and $200 \mathrm{ng}$ & $400 \mathrm{ng}$ and $800 \mathrm{ng}$ \\
\hline
\end{tabular}

whole cells, the four test discs were replaced by spotting four $10 \mu \mathrm{l}$ drops of dense AURA culture directly onto the agar). After test and control solutions had been applied and the plates allowed to dry, E. coli (DH5a) culture was inoculated onto the agar by means of a misting nebulizer. Duplicate plates were incubated at $37^{\circ} \mathrm{C}$ for $12-18$ hours. Observation of plates established if zones of clearance were present or absent.

\subsection{Minimum Inhibitory Concentration (Broth Microdilution)}

The following bacterial stains were selected as per VICH GL36 (R) guidelines [28] and procured from the American Type Culture Collection (Manassas, VA, USA) (Table 2).

\section{Minimum inhibitory concentration determination}

The experiments were carried out in accordance with CLSI M07-A9 guidelines using the Broth macro-dilution method at ABC Laboratories (Gainesville, FL, USA) [37]. Each product was tested separately with each microorganism under aerobic, anaerobic or microaerobic growth conditions as appropriate. Inocula were initially prepared on solid media, Trypticase Soy Agar (TSA) under aerobic conditions for $E$. coli and $E$. faecalis, TSA with 5\% Sheep blood (SBA) under anaerobic organisms for B. fragilis, B. longum, C. aerofaciens, F. canifelinum, $P$. anaerobius and $C$. difficile while $L$. brevis was prepared on de Mann, Rogosa Sharpe (MRS) agar under microaerobic conditions. Colonies were selected and suspended in sterile $0.85 \%$ saline in order to obtain optical densities of $2.0 \mathrm{McF}$ arland prior to the experiment.

\section{Aerobic analysis}

Serial dilutions (1:1) $(n=13)$ of algal powder and algal oil suspensions were separately prepared in Mueller Hinton Broth (MHB) to obtain 1\% down to $0.0002441406 \%$ test concentrations. Positive and negative controls were similarly prepared in MHB. $10 \mu \mathrm{l}$ volumes were inoculated into each broth suspension to form an initial concentration of ca. $1 \times 10^{5} \mathrm{CFU} / \mathrm{ml}$. Dilution tubes were incubated aerobically at $35^{\circ} \mathrm{C} \pm 2^{\circ} \mathrm{C}$ for $18-20$ hours.

\section{Anaerobic analysis}

Serial dilutions (1:1) $(n=13)$ of algal powder and algal oil suspensions were separately prepared in Brucella Broth with Hemin and Vitamin $\mathrm{K}^{1}$ to obtain $1 \%$ down to $0.0002441406 \%$ test concentrations. Positive and negative controls were similarly prepared in supplemented Brucella Broth. $10 \mu \mathrm{l}$ volumes were inoculated 
Table 2. Strains selected for broth macro dilution MIC analysis.

\begin{tabular}{cc}
\hline Organism & Source of Isolation \\
\hline Bacteroides fragilis ATCC $^{\circ} 25285^{\mathrm{TM}}$ & Appendix abscess \\
Bifidobacterium longum ATCC $^{\circ} 15707^{\mathrm{TM}}$ & Intestine of Adult \\
Clostridium difficile ATCC $700057^{\mathrm{TM}}$ & Not specified; application: susceptibility testing \\
Enterococcus faecalis ATCC $^{\circ} 51299^{\mathrm{TM}}$ & Peritoneal fluid \\
Escherichia coli ATCC $25922^{\mathrm{TM}}$ & Clinical isolate \\
Collinsella aerofaciens ATCC $^{\circ} 29738^{\mathrm{TM}}$ & Human faeces \\
Fusobacterium canifelinum ATCC $^{\circ} \mathrm{BAA}^{\mathrm{TM}} 689^{\mathrm{TM}}$ & Clinical specimen, human, dog-bite wound \\
Lactobacillus brevis ATCC $^{\circ} 14869^{\mathrm{TM}}$ & Human faeces \\
Peptostreptococcus anaerobius ATCC $^{\circ} 27337^{\mathrm{TM}}$ & Not specified; application: QC testing \\
\hline
\end{tabular}

into each broth suspension to form an initial concentration of ca. $1 \times 10^{5} \mathrm{CFU} / \mathrm{ml}$. Dilution tubes were incubated anaerobically at $36^{\circ} \mathrm{C} \pm 1^{\circ} \mathrm{C}$ for $46-48$ hours $(B$. fragilis and $B$. longum) or at $36^{\circ} \mathrm{C} \pm 1^{\circ} \mathrm{C}$ for $70-72$ hours (C. difficile, C. aerofaciens, $F$. canifelinum and $P$. anaerobius).

\section{Microaerobic analysis}

Serial dilutions (1:1) $(n=13)$ of algal powder and algal oil suspensions were separately prepared in MRS Broth to obtain $1 \%$ down to $0.0002441406 \%$ test concentrations. Positive and negative controls were similarly prepared in MRS Broth. $10 \mu \mathrm{l}$ volumes were inoculated into each broth suspension to form an initial concentration of ca. $3 \times 10^{5} \mathrm{CFU} / \mathrm{ml}$. Dilution tubes were incubated microaerobically at $30^{\circ} \mathrm{C} \pm 2^{\circ} \mathrm{C}$ for $46-48$ hours.

Following incubation, tubes containing MHB, supplemented Brucella Broth and MRS Broth were examined and scored positive or negative for turbidity. The MIC was determined from the lowest concentration of test material that acted to completely inhibit bacterial growth.

\subsection{Algal Toxin Analysis}

\section{Polyketide analysis}

The presence of "Golden algae" polyketides was carried out by LC/MS metabolic fingerprinting. Whole cells were selected during mid-exponential phase and concentrated through centrifugation. Cellular extracts and supernatant extracts were prepared as per [35]. Extract fractions were suspended in 5\% methanol solution before being diluted to $1 \mu \mathrm{g} / \mu \mathrm{l}$ for LC/MS analysis. Spectra were collated and peaks in the $900-1200 \mathrm{~m} / \mathrm{z}$ regions were compared to peaks for known polyketides.

\section{Domoic acid and epi-domoic acid analysis}

Unextracted Aurantiochytrium limacinum (CCAP 4087/2) biomass (produced by Alltech Inc. KY, USA) was supplied to the Marine Institute (Galway, Ireland). Samples were prepared in 50:50 methanol /water solution and extracted through ultrasonication for 15 minutes. HPLC-DAD and UHPLC-DAD analysis for the 
presence of domoic acid toxins was carried out according to in-house protocols.

\subsection{Contaminants, Residues and Undesirables}

These analyses were carried out by Minnesota Valley Testing Laboratories Inc (Minnesota, USA) in compliance with current Good Laboratory Practices (GLP) guidelines (21 CFR part 58) according to the methods indicated in Table 3.

\section{Results}

\subsection{Biochemical Profiling}

Proximate analysis confirmed the oleaginous nature of the unextracted Aurantiochytrium biomass with an average $72.85 \%$ crude fat in the sample (Table 4). Percentages of crude protein, moisture and ash are all low $(11.44 \%, 3.10 \%$ and $3.39 \%$ respectively), indicating significant conversion of substrate to desirable fatty acids. Table 5 reveals the fatty acid profile and the lipid composition. The major components are palmitic acid (average $36.35 \% \mathrm{w} / \mathrm{w}$ ) and docosahexaenoic acid (average $18.17 \% \mathrm{w} / \mathrm{w}$ ). The total polyunsaturated fat content in the AURA biomass is $18.83 \% \mathrm{w} / \mathrm{w}$ of which DHA constitutes the greatest proportion.

\subsection{S rRNA Identification}

The partial 18S sequence assembled from the genetic identification can be seen in Figure 1. When compared to the NCBI BLAST database, the test strain was determined to be most comparable to the following six protists; Aurantiochytrium Sp. ST-2012 clone BJ61 (Genbank: JQ982491.1), Aurantiochytrium Sp. TF81 (Genbank: KM023695.1), Aurantiochytrium Sp. TF23 (Genbank: KM023689.1), Aurantiochytrium Sp. LY-2012 isolate PKU\#Sed1 (Genbank: JX847370.1), Aurantiochytrium Sp. LY-2012 isolate PKU\#MN7 (Genbank: JX847363.1), Aurantiochytrium Sp.

TGTGTNNGTATAAGCGATTGTACTGTGAGACTGCGAACGGCTCATTATATCAGTAATAATTTCTTCGGTAGTT TCTTTTATATGGATACCTGCAGTAATTCTGGAAATAATACATGCTGTAAGAGCCCTGTATGGGGCTGCACTTAT TAGATTGAAGCCGATTTTATTGGTGAATCATGATAATTGAGCAGATTGACTTTTT * TCGATGAATCGTTTGAGTTTCTGCCCCATCAGTTGTCGACGGTAGTGTATTGGACTACGGTGACTATAACGGG TGACGGAGAGTTAGGGCTCGACTCCGGAGAGGGAGCCTGAGAGACGGCTACCATATCCAAGGATAGCNNNN GGCGCGTA * ATCTTTCACTGTAATCAAAGCAGAGTGTTCCAAGCAGGTCGTATGACCGGTATGTTTATTATGGGATGATAAG ATAGGACTTGGGTGCTATTTTGTTGGTTTGCACGCCTGAGTAATGGTTAATAGGAACAGTTGGGGGTATTCGT ATTTAGGAGCTAGAGGTGAAATTCTNGGATTTCCGAAAGACGAACNAGAGCGAAGGC * GGAATTGAGTGCTTGGTCGGAAGGCCTGGCTAATCCTTGGAACGCTCATCGTGCTGGGGCTAGATTTTTGCAA TTATTAATCTCCAACGAGGAATTCCTAGTAAACGCAAGTCATCAGCTTGCATTGAATACGTCCCTGCCCTTTGT ACACACCGCCCGTCGCACCTACCGATTGAACGGTCCGATGAAACCATGGGANNTNNNTGTTTGGATNNATTT TNGGACAGAGGCAGAACNNNGGGNNANTCTTA

*Indicates gapped region

Figure 1. Analysis of the lipid composition and fatty acid profile of unextracted Aurantiochytrium limacinum biomass (AURA) in accordance with GLP principles. 
Table 3. Analytes and analytical methods for evaluation of contaminants, residues and other undesirables in unextracted AURA biomass following heterotrophic fermentation.

\begin{tabular}{|c|c|}
\hline Analyte & Method \\
\hline \multicolumn{2}{|l|}{ Minerals } \\
\hline Copper (mg/kg) & AOAC $985.01[38]$ \\
\hline Calcium (mg/kg) & AOAC $985.01[38]$ \\
\hline Iron (mg/kg) & AOAC $985.01[38]$ \\
\hline Magnesium (mg/kg) & AOAC $985.01[38]$ \\
\hline Manganese (mg/kg) & AOAC $985.01[38]$ \\
\hline Potassium (mg/kg) & AOAC $985.01[38]$ \\
\hline Sodium (mg/kg) & AOAC $985.01[38]$ \\
\hline Sulfur (mg/kg) & AOAC $985.01[38]$ \\
\hline Zinc (mg/kg) & AOAC $985.01[38]$ \\
\hline Selenium $(\mathrm{mg} / \mathrm{kg})$ & $9.2669 \mathrm{ISU}$ \\
\hline Fluoride (mg/kg) & AOAC 975.08 [39] \\
\hline \multicolumn{2}{|l|}{ Heavy Metals } \\
\hline Antimony (mg/kg) & SW-846 $6020[40]$ \\
\hline Arsenic (mg/kg) & SW-846 $6020[40]$ \\
\hline Cadmium (mg/kg) & SW-846 $6020[40]$ \\
\hline Lead (mg/kg) & SW-846 6020 [40] \\
\hline Mercury (mg/kg) & ASTM D6722 [41] \\
\hline \multicolumn{2}{|l|}{ Microbial } \\
\hline Aerobic Plate count (cfu/g) & FDA/BAM Chapter 3 [42] \\
\hline Coliform Count (cfu/g) & FDA/BAM Chapter 4 [43] \\
\hline Escherichia coli (cfu/g) & FDA/BAM Chapter 4 [43] \\
\hline Staphylococci Confirm (cfu/g) & FDA/BAM Chapter 12 [44] \\
\hline Mould Count (cfu/g) & FDA/BAM Chapter 18 [45] \\
\hline Yeast Count (cfu/g) & FDA/BAM Chapter 18 [45] \\
\hline Pseudomonas (cfu/g) & Chromagar/Difco BBL \\
\hline Clostridium (cfu/g) & CMMEF chapter 34 [46] \\
\hline Salmonella( / $25 \mathrm{~g})$ & FDA/BAM Chapter 5 [47] \\
\hline Listeria (cfu/g) & FDA/BAM Chapter 10 [48] \\
\hline \multicolumn{2}{|l|}{ Spoilage } \\
\hline Peroxide Value (meq/kg fat) & AOAC 965.33 [49] \\
\hline \multicolumn{2}{|l|}{ Mycotoxins } \\
\hline \multicolumn{2}{|l|}{ Aflatoxin B1 (ppb) } \\
\hline \multicolumn{2}{|l|}{ Aflatoxin G1 (ppb) } \\
\hline Aflatoxin B2 (ppb) & “Vicam Manual Mod" \\
\hline Aflatoxin G2 (ppb) & (modification of the BAM \\
\hline Deoxynivalenol (Vomitoxin) (ppm) & (Chapter 18) method [45]). \\
\hline \multicolumn{2}{|l|}{ Ochratoxin A (ppb) } \\
\hline \multicolumn{2}{|l|}{ Zearalenone (ppm) } \\
\hline \multicolumn{2}{|l|}{ Pesticides } \\
\hline Residues as indicated in Table 11. & Modification of EPA 8081 method [50] \\
\hline
\end{tabular}

9.2669 ISU-internal method code for Iowa State University; Chromagar/Difco BBL_proprietary enumeration method on chromogenic agar. 
Table 4. Proximate analysis by weight of unextracted Aurantiochytrium limacinum biomass (AURA) in accordance with GLP principles $(\mathrm{n}=5)$.

\begin{tabular}{ccc}
\hline \multirow{2}{*}{ Analyte } & \multicolumn{2}{c}{ Batch Analysis Results $(\mathrm{N}=5)$} \\
\cline { 2 - 3 } & Range (\%) & Average (\%) \\
\hline Crude Protein & $8.32-15.8$ & 11.44 \\
Crude Fat & $70.21-77.25$ & 72.85 \\
Moisture & $2.27-5.57$ & 3.10 \\
Ash & $2.41-3.92$ & 3.39 \\
\hline
\end{tabular}

Table 5. Analysis of the lipid composition and fatty acid profile of unextracted Aurantiochytrium limacinum biomass (AURA) in accordance with GLP principles.

\begin{tabular}{|c|c|c|}
\hline \multirow{2}{*}{ Fatty acid } & \multicolumn{2}{|c|}{ Batch Analysis Results $(\mathrm{N}=5)$} \\
\hline & Range (\%) & Average (\%) \\
\hline C10:0 (Capric acid) & $0.010-0.017$ & 0.013 \\
\hline C12:0 (Lauric acid) & $0.112-0.156$ & 0.128 \\
\hline C13:0 (Tridecanoic acid) & $0.016-0.021$ & 0.019 \\
\hline C14:0 (Myristic acid) & $3.020-3.702$ & 3.475 \\
\hline C15:0 (Pentadecanoic acid) & $1.050-1.283$ & 1.135 \\
\hline C16:0 (Palmitic acid) & $34.512-38.228$ & 36.351 \\
\hline C16:1 (Palmitoleic acid) & $0.062-0.146$ & 0.101 \\
\hline C17:0 (Magaric acid) & $0.308-0.440$ & 0.363 \\
\hline C18:0 (Stearic acid) & $0.982-1.197$ & 1.069 \\
\hline C18:1 (Oleic acid) & $0.099-0.274$ & 0.174 \\
\hline C18:2 (t-Octadecadienoic acid) & $0.026-0.062$ & 0.043 \\
\hline C18:2 (Linoleic acid) & $0.004-0.466$ & 0.098 \\
\hline C20:0 (Arachidic acid) & $0.103-0.186$ & 0.145 \\
\hline C18:3 (g-Linolenic acid) & $0.020-0.035$ & 0.025 \\
\hline C18:3 (Linolenic acid) & $0.014-0.129$ & 0.045 \\
\hline C22:0 (Behenic acid) & $0.058-0.095$ & 0.077 \\
\hline C20:3 (g-Eicosatrienoic acid) & $0.061-0.101$ & 0.075 \\
\hline C20:3 (Eicosatrienoic acid) & $0.353-0.723$ & 0.554 \\
\hline C20:4 (Arachidonic acid) & $0.050-0.067$ & 0.054 \\
\hline C22:2 (Docosadienoic acid) & $0.005-0.296$ & 0.162 \\
\hline C24:0 (Lignoceric acid) & $0.057-0.317$ & 0.161 \\
\hline C20:5 (Eicosapentaenoic acid) & $0.212-0.338$ & 0.271 \\
\hline C22:3 (Docosatrienoic acid) & $0.006-0.053$ & 0.029 \\
\hline C22:5 (Docosapentaenoic acid) & $0.030-0.070$ & 0.046 \\
\hline C22:6 (Docosahexaenoic acid) & $16.920-19.837$ & 18.174 \\
\hline Total saturated fatty acids & $39.380-42.330$ & 40.916 \\
\hline Total monounsaturated fatty acids & $0.170-0.370$ & 0.280 \\
\hline Total polyunsaturated fatty acids & $17.320-20.520$ & 18.834 \\
\hline Total trans fatty acids & $0.040-0.090$ & 0.066 \\
\hline Total fatty acids & $58.15-61.40$ & 60.096 \\
\hline Total fat as triglycerides & $60.83-63.61$ & 62.874 \\
\hline
\end{tabular}

Results are reported in terms of weight of ingredient. 
isolate SL1101 (Genbank: JN986842.1). Furthermore, taking into account the fatty acid profile, the protist reveals itself to be similar to Aurantiochytrium sp. as determined by [51].

\subsection{Minimum Inhibitory Concentration (Disc Diffusion)}

As revealed by the results in Table 6, uninhibited growth of E. coli (DH5a) was observed at all test application points. Concurrently, inhibition was observed in the presence of the positive control organisms while no inhibition was observed with the negative controls. These results indicate that at low concentrations, Aurantiochytrium cells and cellular extracts thereof pose no observable antimicrobial threat to the reference organism through DHA production or the presence of secondary metabolites.

\subsection{Minimum Inhibitory Concentration (Broth Microdilution)}

The experimental results manifested in Table 7 and Table 8 display the turbidity scores for each microorganism against the respective concentration of test material. Turbidity was evident in test suspensions between $1 \%$ and $0.0625 \%$ concentrations (owing to the presence of the test materials) prior to incubation and was noted to have increased following incubation. All 13 dilution tubes for each microorganism and test material combination were positively scored following incubation, indicating that none of the nine intestinal microorganisms were inhibited by DHA-rich algae powder nor the extracted oil at concentrations up to at least $0.03125 \%$ (owing to the initial turbidity at concentrations above $0.03125 \%)$

\subsection{Algal Toxin Analysis}

LC/MS spectra for both the cell fraction extract and the supernatant fraction extracts (Figure 2 and Figure 3) were compared to the Golden Algae spectra in

Table 6. Minimum inhibitory concentration (MIC) of Aurantiochytrium extracts or whole cell culture in the presence of $E$. coli (DH5a).

\begin{tabular}{ccccc}
\hline Analyte & \multicolumn{4}{c}{ Test concentration } \\
Test materials & & & \\
Whole cell culture & Drop 1 (+) & Drop 2 (+) & Drop 3 (+) & Drop 4 (+) \\
Cellular extracts & $10 \mu \mathrm{g}(+)$ & $20 \mu \mathrm{g}(+)$ & $40 \mu \mathrm{g}(+)$ & $80 \mu \mathrm{g}(+)$ \\
Supernatant extract & $10 \mu \mathrm{g}(+)$ & $20 \mu \mathrm{g}(+)$ & $40 \mu \mathrm{g}(+)$ & $80 \mu \mathrm{g}(+)$ \\
Positive controls & & & \\
Ampicillin & $100 \mu \mathrm{g}(-)$ & $200 \mu \mathrm{g}(-)$ & $1 \mathrm{mg}(-)$ & $2 \mathrm{mg}(-)$ \\
Streptomycin & $100 \mu \mathrm{g}(-)$ & $200 \mu \mathrm{g}(-)$ & $400 \mu \mathrm{g}(-)$ & $800 \mu \mathrm{g}(-)$ \\
Negative control & $5 \%$ Methanol (+) & $5 \%$ Methanol (+) \\
\hline
\end{tabular}

$(+)$ indicates growth around the treatment point; $(-)$ indicates inhibition of growth around the treatment point. 
Table 7. Minimum Inhibitory Concentration (MIC) of unextracted Aurantiochytrium limacinum powder in the presence of selected microorganisms.

\begin{tabular}{|c|c|c|c|c|c|c|c|c|c|c|}
\hline $\begin{array}{l}\text { Test } \\
\text { Tube }\end{array}$ & $\begin{array}{c}\text { AURA powder } \\
\text { concentration }(\%)\end{array}$ & $\begin{array}{l}E \\
\text { coli }\end{array}$ & $\begin{array}{c}E . \\
\text { faecalis }\end{array}$ & $\begin{array}{c}B . \\
\text { fragilis }\end{array}$ & $\begin{array}{c}\text { B. } \\
\text { longum }\end{array}$ & $\begin{array}{c}C . \\
\text { difficile }\end{array}$ & $\begin{array}{c}F \\
\text { canifelinum }\end{array}$ & $\begin{array}{c}C . \\
\text { aerofaciens }\end{array}$ & $\begin{array}{c}P . \\
\text { anaerobius }\end{array}$ & $\begin{array}{c}L . \\
\text { brevis }\end{array}$ \\
\hline 1 & 1 & + & + & + & + & + & + & + & + & + \\
\hline 2 & 0.5 & + & + & + & + & + & + & + & + & + \\
\hline 3 & 0.25 & + & + & + & + & + & + & + & + & + \\
\hline 4 & 0.125 & + & + & + & + & + & + & + & + & + \\
\hline 5 & 0.0625 & + & + & + & + & + & + & + & + & + \\
\hline 6 & 0.03125 & + & + & + & + & + & + & + & + & + \\
\hline 7 & 0.015625 & + & + & + & + & + & + & + & + & + \\
\hline 8 & 0.0078125 & + & + & + & + & + & + & + & + & + \\
\hline 9 & 0.00390625 & + & + & + & + & + & + & + & + & + \\
\hline 10 & 0.001953125 & + & + & + & + & + & + & + & + & + \\
\hline 11 & 0.000976563 & + & + & + & + & + & + & + & + & + \\
\hline 12 & 0.000488281 & + & + & + & + & + & + & + & + & + \\
\hline 13 & 0.000244141 & + & + & + & + & + & + & + & + & + \\
\hline \multicolumn{2}{|c|}{ Positive control } & + & + & + & + & + & + & + & + & + \\
\hline \multicolumn{2}{|c|}{ Negative control } & - & - & - & - & - & - & - & - & - \\
\hline
\end{tabular}

+ indicates turbidity (growth) in the culture medium; - indicates an absence of turbidity (no growth) in the culture medium.

Table 8. Minimum Inhibitory Concentration (MIC) of extracted Aurantiochytrium limacinum powder in the presence of selected microorganisms.

\begin{tabular}{|c|c|c|c|c|c|c|c|c|c|c|}
\hline $\begin{array}{l}\text { Test } \\
\text { Tube }\end{array}$ & $\begin{array}{c}\text { AURA powder } \\
\text { concentration }(\%)\end{array}$ & $\begin{array}{l}E \\
\text { coli }\end{array}$ & $\begin{array}{c}E \\
\text { faecalis }\end{array}$ & $\begin{array}{c}B . \\
\text { fragilis }\end{array}$ & $\begin{array}{c}\text { B. } \\
\text { longum }\end{array}$ & $\begin{array}{c}C . \\
\text { difficile }\end{array}$ & $\begin{array}{c}F \\
\text { canifelinum }\end{array}$ & $\begin{array}{c}C . \\
\text { aerofaciens }\end{array}$ & $\begin{array}{c}P . \\
\text { anaerobius }\end{array}$ & $\begin{array}{c}L . \\
\text { brevis }\end{array}$ \\
\hline 1 & 1 & + & + & + & + & + & + & + & + & + \\
\hline 2 & 0.5 & + & + & + & + & + & + & + & + & + \\
\hline 3 & 0.25 & + & + & + & + & + & + & + & + & + \\
\hline 4 & 0.125 & + & + & + & + & + & + & + & + & + \\
\hline 5 & 0.0625 & + & + & + & + & + & + & + & + & + \\
\hline 6 & 0.03125 & + & + & + & + & + & + & + & + & + \\
\hline 7 & 0.015625 & + & + & + & + & + & + & + & + & + \\
\hline 8 & 0.0078125 & + & + & + & + & + & + & + & + & + \\
\hline 9 & 0.00390625 & + & + & + & + & + & + & + & + & + \\
\hline 10 & 0.001953125 & + & + & + & + & + & + & + & + & + \\
\hline 11 & 0.000976563 & + & + & + & + & + & + & + & + & + \\
\hline 12 & 0.000488281 & + & + & + & + & + & + & + & + & + \\
\hline 13 & 0.000244141 & + & + & + & + & + & + & + & + & + \\
\hline \multicolumn{2}{|c|}{ Positive control } & + & + & + & + & + & + & + & + & + \\
\hline \multicolumn{2}{|c|}{ Negative control } & - & - & - & - & - & - & - & - & - \\
\hline
\end{tabular}

+ indicates turbidity (growth) in the culture medium; - indicates an absence of turbidity (no growth) in the culture medium. 


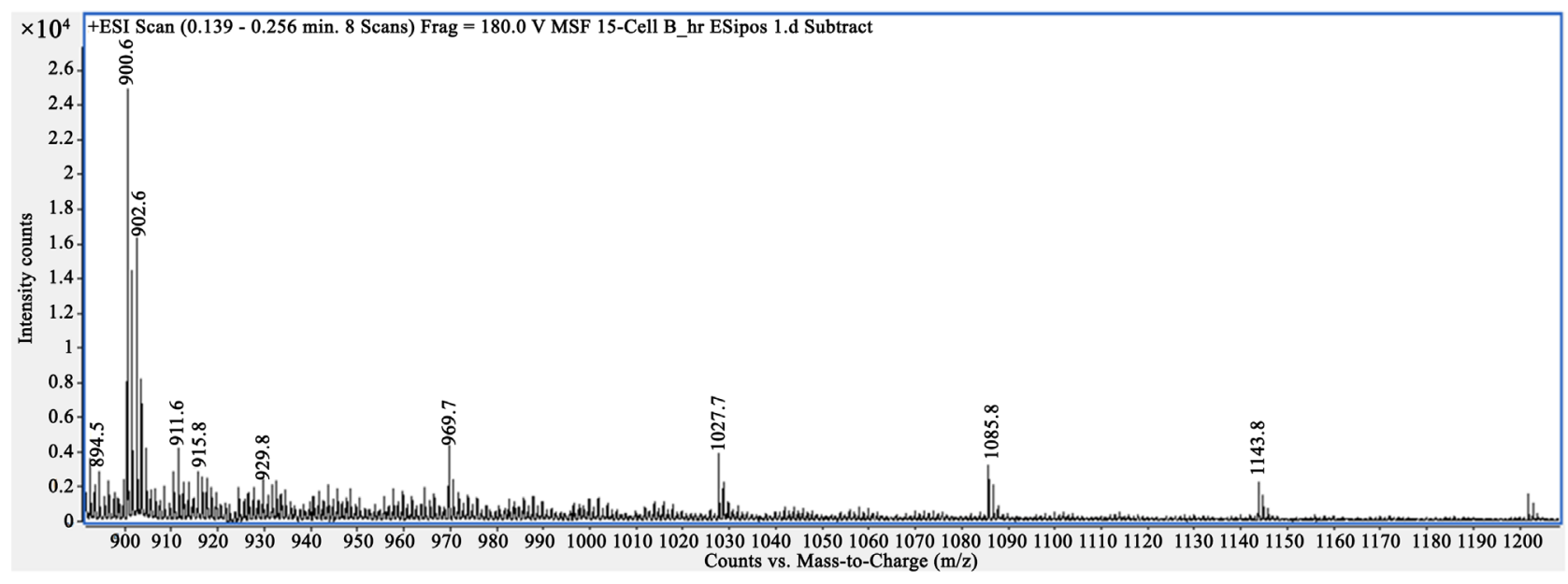

Figure 2. Spectra form LC/MS analysis of Aurantiochytrium limacinum cell fraction extract.

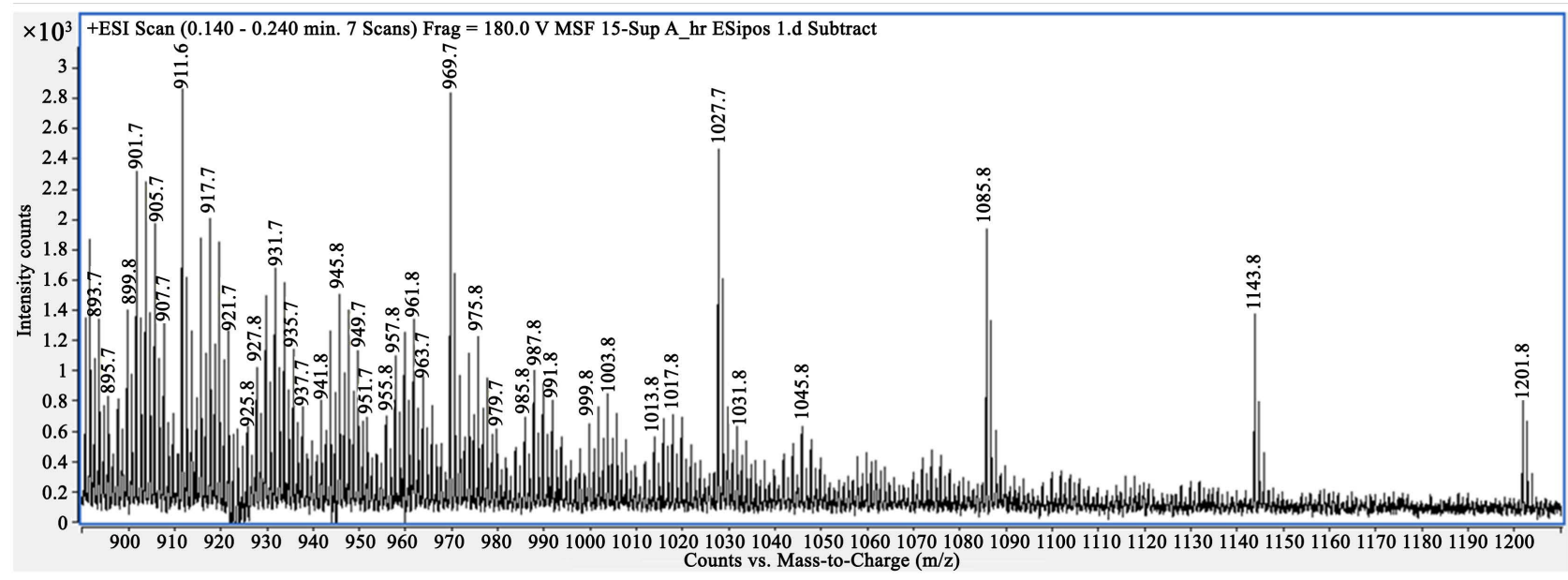

Figure 3. Spectra form LC/MS analysis of Aurantiochytrium limacinum supernatant fraction extract.

[35]. Polyketide prymnesinspectral peaks, based on spiked controls, would have been evident at $985.89^{2+} \mathrm{m} / \mathrm{z}$ and $1141.44^{2+} \mathrm{m} / \mathrm{z}$ for Prym 1 or $919.88^{2+} \mathrm{m} / \mathrm{z}$ and $1141.44^{2+} \mathrm{m} / \mathrm{z}$ for Prym2. While phenotypically similar, Aurantiochytrium limacinum is phylogenetically distant from golden algae and proved to have a dissimilar metabolic fingerprint when compared to the spectra of polyketide producing Prymnesium parvum. None of the spectral peaks aligned with known polyketides, indicating that this organism is unlikely to pose a threat in terms of production of such algal toxins. Moreover, as evidenced by the additional analyses for the presence of Domoic and epi-domoic acids in unextracted AURAbiomass samples (Table 9); Aurantiochytrium limacinum has not been found to produce any of the frequently observed marine algal toxins.

\subsection{Contaminants, Residues and Undesirables}

The results of the further assessment for heavy metals, pesticides and other undesirables from industrial fermentation can be seen in Table 10 and Table 11. These analyses are significant in that they demonstrate that the Aurantiochytrium 
Table 9. Domoic and epi-domoic acid analysis of unextracted Aurantiochytrium limacinum biomass $(A U R A)$.

\begin{tabular}{cc}
\hline Batch\# & Source of Isolation \\
\hline 1 & $<0.25 \mu \mathrm{g} / \mathrm{g}$ \\
2 & $<0.25 \mu \mathrm{g} / \mathrm{g}$ \\
3 & $<0.25 \mu \mathrm{g} / \mathrm{g}$ \\
4 & $<0.25 \mu \mathrm{g} / \mathrm{g}$ \\
5 & $<0.25 \mu \mathrm{g} / \mathrm{g}$ \\
\hline
\end{tabular}

Table 10. Mineral, heavy metal, microbial pathogen, spoilage and toxin analysis of unextracted Aurantiochytrium limacinum biomass (AURA) in accordance with GLP principles.

\begin{tabular}{|c|c|c|}
\hline \multirow{2}{*}{ Analyte } & \multicolumn{2}{|c|}{ Batch Analysis Results $(\mathrm{N}=5)$} \\
\hline & Range & Average \\
\hline \multicolumn{3}{|l|}{ Minerals } \\
\hline Copper (mg/kg) & - & $<1.24$ \\
\hline Calcium (mg/kg) & $2736-3810$ & 3353.2 \\
\hline Iron $(\mathrm{mg} / \mathrm{kg})$ & - & $<12.5$ \\
\hline Magnesium (mg/kg) & $2482-3312$ & 2833.6 \\
\hline Manganese (mg/kg) & - & $<1.25$ \\
\hline Potassium (mg/kg) & $1633-3208$ & 2228.4 \\
\hline Sodium (mg/kg) & $1104-1539$ & 1277.8 \\
\hline Sulfur (mg/kg) & $5248-7047$ & 6013.2 \\
\hline Zinc (mg/kg) & $3.74-36.81$ & 20.722 \\
\hline Selenium (mg/kg) & $<0.02$ & $<0.02$ \\
\hline Fluoride $(\mathrm{mg} / \mathrm{kg})$ & $<5-8.49$ & $<5.794$ \\
\hline \multicolumn{3}{|l|}{ Heavy Metals } \\
\hline Antimony (mg/kg) & $<0.025$ & $<0.025$ \\
\hline Arsenic (mg/kg) & 0.192 & 0.259 \\
\hline Cadmium (mg/kg) & $<0.005$ & $<0.005$ \\
\hline Lead (mg/kg) & $<0.025$ & $<0.025$ \\
\hline Mercury (mg/kg) & $<0.02$ & $<0.02$ \\
\hline \multicolumn{3}{|l|}{ Microbial } \\
\hline Aerobic Plate count (cfu/g) & $40-450$ & 354 \\
\hline Coliform Count (cfu/g) & $<10$ & $<10$ \\
\hline Escherichia coli (cfu/g) & $<10$ & $<10$ \\
\hline Staphylococci Confirm (cfu/g) & $<10$ & $<10$ \\
\hline Mould Count (cfu/g) & $<10-20$ & $14^{*}$ \\
\hline Yeast Count (cfu/g) & $<10$ & $<10$ \\
\hline
\end{tabular}




\section{Continued}

\begin{tabular}{ccc}
\hline Pseudomonas $(\mathrm{cfu} / \mathrm{g})$ & $<1$ & $<1$ \\
Clostridium $(\mathrm{cfu} / \mathrm{g})$ & $<100$ & $<100$ \\
Salmonella $(/ 25 \mathrm{~g})$ & Negative & Negative \\
Listeria $(\mathrm{cfu} / \mathrm{g})$ & Negative & Negative \\
Spoilage & & \\
Peroxide Value $(\mathrm{meq} / \mathrm{kg}$ fat $)$ & $<0.2-18.5$ & 3.86 \\
Mycotoxins & $<3$ & $<3$ \\
Aflatoxin B1 (ppb) & $<15$ & $<15$ \\
Aflatoxin G1 (ppb) & $<1$ & $<1$ \\
Aflatoxin B2 (ppb) & $<5$ & $<5$ \\
Aflatoxin G2 (ppb) & $<0.2$ & $<0.2$ \\
Deoxynivalenol (Vomitoxin) $(\mathrm{ppm})$ & $<12.5$ & $<12.5$ \\
Ochratoxin A (ppb) & $<0.1$ & $<0.1$ \\
Zearalenone (ppm) &
\end{tabular}

$\mathrm{cfu}=$ colony forming units; $\mathrm{ND}=$ not detected; $\mathrm{meq}=$ milliequivalent ppb = parts per billion; $\mathrm{ppm}=$ parts per million; ${ }^{\star}$ Assuming $\mathrm{ND}=0$.

Table 11. Pesticides in unextracted Aurantiochytrium limacinum biomass (AURA) in accordance with GLP principles.

\begin{tabular}{cc}
\hline Pesticide & Result (ppm) \\
\hline Aldrin & $<0.01$ \\
alpha-benzene hexachloride & $<0.01$ \\
beta-benzene hexachloride & $<0.01$ \\
delta-benzene hexachloride & $<0.01$ \\
Carbophenothion (Trithion) & $<0.15$ \\
alpha-Chlordane & $<0.01$ \\
gamma-Chlordane & $<0.01$ \\
Diazinon & $<0.14$ \\
Dieldrin & $<0.02$ \\
Disulfoton & $<0.15$ \\
Endosulfan (Thiodan) & $<0.02$ \\
Endrin & $<0.03$ \\
Ethion & $<0.14$ \\
Heptachlor & $<0.01$ \\
Heptachlor epoxide & $<0.01$ \\
Hexachlorobenzene & $<0.01$ \\
Lindane & $<0.01$ \\
Malathion & $<0.01$ \\
Methoxychlor & $<0.05$ \\
\hline
\end{tabular}




\section{Continued}

\begin{tabular}{cc}
\hline Methyl parathion & $<0.14$ \\
Mirex & $<0.01$ \\
Parathion & $<0.12$ \\
Phorate (Thimet) & $<0.15$ \\
Ronnel & $<0.13$ \\
Toxaphene & $<0.05$ \\
$2,4^{\prime}-$ DDD & $<0.03$ \\
$4,4^{\prime}-$ DDD & $<0.02$ \\
$2,4^{\prime}-$ DDE & $<0.11$ \\
$4,4^{\prime}-$ DDE & $<0.02$ \\
$2,4^{\prime}-$ DDT & $<0.03$ \\
$4,4^{\prime}-$ DDT & $<0.03$ \\
\hline
\end{tabular}

DDD = Dichlorodiphenyldichloroethane; DDE $=$ Dichlorodiphenyldichloroethylene; $\mathrm{DDT}=$ dichlorodiphenyltrichloroethane.

production process itself is safe and fit for purpose. Industrial scale heterotrophic fermentation did not show any indications of elevated heavy metal accumulation, hygiene indicator organisms and microbial pathogens were all absent and mycotoxin contaminant levels were below the limits of detection. Similarly, pesticide residue levels were below the limits of detection for these analytical methods. Copper and selenium levels were shown to be low, which is pertinent as AURA is intended to be used as a DHA rich feed material for food producing animals, many of which can be sensitive to the presence of high concentrations of these minerals.

\section{Discussion and Conclusions}

Originally isolated from the marine environment off the Floridian coast, the oleaginous protist studied here showed early promise as a source of polyunsaturated fatty acids. Biochemical profiling revealed not only that the organism produced in excess of $70 \%$ crude fat, but that $18 \%$ of the fatty acid content was docosahexaenoic acid (DHA). This compared favorably with alternative terrestrial sources [52] and placed the protist as a viable source of DHA, and as an alternative to fish-oil derived DHA for dietary inclusion in aquaculture and animal nutrition. Microscopic and biochemical analyses had identified the organism as a member of the Thraustochytriaceae family. As phenotypic classification could not resolve the species identity, this was confirmed as Aurantiochytrium limacinum through $18 \mathrm{~S}$ rRNA profiling.

Having established the potential of AURA as a commercial DHA source, attention was focused on the safety of the organism. Every novel isolate has the potential to be a producer of bioactive secondary metabolites and other organisms from the marine environment are known to produce toxic metabolites. 
"Golden algae" are a group of algal protists that are morphologically similar to Aurantiochytrium and are producers of toxic polyketides such as prymnesin-1 (prym1) and prymnesin-2 (prym2) [35]. LC/MS spectra from Aurantiochytrium extracts revealed no correlation with spectral signatures of known polyketides. Similarly, the analysis for domoic and epi-domoic acid production revealed AURA not to be a producer of these neurotoxic compounds. Having established biochemically that known toxins were absent, analysis was carried out to ascertain whether cellular mass or extracts thereof would have inhibitory effects on an indicator organism. Despite dosing with up to $80 \mu \mathrm{g}$ of AURA extracts, no inhibition was observed in the E. coli (DH5a) population. Cumulatively therefore, there is no evidence that this strain of Aurantiochytrium limacinum poses any particular threat to an animal or to the microflora therewith.

Ascertaining that there was no production of known microalgal toxins nor gross antimicrobial effects, attention was turned to the primary desirable component (DHA) and the effect it may have on the microbiota of food-producing animals. Details are limited on the degree to which DHA supplementation into the diet can influence commensal bio-flora populations, however some inference can be made from the effect DHA can have on microorganisms from other environments. MICs for an extracted DHA exist for a range of foodborne pathogens; Bacillus subtilis ( $350 \mu \mathrm{g} / \mathrm{ml})$, Listeria monocytogenes $(350 \mu \mathrm{g} / \mathrm{ml})$, Staphylococcus aureus $(500 \mu \mathrm{g} / \mathrm{ml})$, Pseudmonas aeruginosa $(250 \mu \mathrm{g} / \mathrm{ml})$, E. coli O157:H7 $(1650 \mu \mathrm{g} / \mathrm{ml})$, Enterobacter aerogenes $(4800 \mu \mathrm{g} / \mathrm{ml})$, Salmonella enteritidis $(1650 \mu \mathrm{g} / \mathrm{ml})$ and Salmonella typhimurium $(1650 \mu \mathrm{g} / \mathrm{ml})$ [53]. Owing to the potential clinical application in the treatment of oral health conditions, MICs have been determined for a range of oral pathogens; Streptococcus mutans (625 $\mu \mathrm{g} / \mathrm{ml})$, Candida albicans $(1250 \mu \mathrm{g} / \mathrm{ml})$, Porphyromonas gingivalis $(9.76 \mu \mathrm{g} / \mathrm{ml})$, Aggregatibacter actinomycetemcimitans $(625 \mu \mathrm{g} / \mathrm{ml})$, Aggregatibacter segnis $(19.53 \mu \mathrm{g} / \mathrm{ml})$, Fusobacterium nucleatum subsp. vinventi $(39.06 \mu \mathrm{g} / \mathrm{ml})$, fusobacterium nucleatum subsp. polymorphum $(39.06 \mu \mathrm{g} / \mathrm{ml})$, Prevotella intermedia $(78.12 \mu \mathrm{g} / \mathrm{ml})$ [54]. It is noteworthy that different strains can exhibit different sensitivities towards DHA; Sun et al. determined MICs for oral pathogens; $P$. gingivalis $(4.11 \mu \mathrm{g} / \mathrm{ml}), F$. nucleatum $(>32.85 \mu \mathrm{g} / \mathrm{ml})$ [55] and $S$. mutans $(32.85$ $\mu \mathrm{g} / \mathrm{ml}$ ) [56]. DHA has shown a tendency to change population dynamics within the rumen through growth inhibition of sensitive organisms. For example, growth of Butyrvibrio fibrisolvens has shown growth inhibition at low concentrations $(50 \mu \mathrm{g} / \mathrm{ml})[4]$.

There is evidence of some antimicrobial or bacteriostatic effects induced by polyunsaturated fatty acids on specific microorganisms [4] [53] [54] [55] [56], and by extension, there is the possibility that DHA derived from supplementation of animal feeds with unextracted Aurantiochytrium limacinum powder or extracted oil, may influence microbial populations in the gut. However, the available experimental data regarding susceptibility of a range of microorganisms to antimicrobial effects of DHA, indicate that the majority of these organisms have an MIC $\geq 312.5 \mu \mathrm{g} / \mathrm{ml}$. There is no body of evidence that suggests 
DHA can promote development of antimicrobial resistance within the food animals or in the realm of public health, in fact [54] states that "to date, no bacterial resistance to free fatty acids has been encountered and no resistance phenotype has emerged". As the US Food and Drug Administration established that the Acceptable daily intake (ADI) for DHA in humans is $3000 \mathrm{mg}$ per day (the European Food Safety Authority set the ADI at 5000 mg per day), it is unlikely that DHA obtained from consumption of food products derived from animals whose diet has been supplemented with AURA, will pose a threat to humans either directly or through promotion of antimicrobial resistance.

The final screening for the presence of microbial pathogens, pesticides and heavy metals showed through their absence that the production process was safe, fit for purpose, and free from manufacturing contaminants. DHA yielded by extracted heterotrophically-grown Aurantiochytrium limacinum (CCAP 4087/2) shows promise to be a safe and environmentally acceptable alternative to traditional marine-harvested fish oils.

\section{Acknowledgements}

The authors express their gratitude to Ms. Lynne Kuchel (Mérieux NutriSciences, USA), Ms. Rebecca Timmons (Alltech Inc. USA) and Ms. Carrie Conn (Alltech Inc. USA) for their technical input and project guidance. The authors thank Ms. Heather Hart (ABC Laboratories, USA) for running the MIC assays and Dr. Schonna Manning (University of Texas at Austin, USA) for her work on the characterization of AURA and for sharing deep knowledge of microalgae, protists and thraustochytrids. Finally, C.A.M. wishes to thank the late Dr. Pearse Lyons (Alltech Inc., USA) for his leadership in sustainable agriculture and significant contributions to the AURA project.

\section{Conflicts of Interest}

The authors declare no conflicts of interest regarding the publication of this paper.

\section{References}

[1] Tan, K., Ma, H., Li, S. and Zheng, H. (2020) Bivalves as Future Source of Sustainable Natural Omega-3 Polyunsaturated Fatty Acids. Food Chemistry, 311, Article ID: 125907. https://doi.org/10.1016/j.foodchem.2019.125907

[2] Scollan, N.D., Choi, N.-J., Kurt, E., Fisher, A.V., Enser, M. and Wood, J.D. (2001) Manipulating the Fatty Acid Composition of Muscle and Adipose Tissue in Beef Cattle. British Journal of Nutrition, 85, 115-124. https://doi.org/10.1079/BJN2000223

[3] Cant, J.P., Fredeen, A.H., MacIntyre, T., Gunn, J. and Crowe, N. (1997) Effect of Fish Oil and Monensin on Milk Composition in Dairy Cows. Canadian Journal of Animal Science, 77, 125-131. https://doi.org/10.4141/A95-125

[4] Maia, M.R., Chaudhary, L.C., Bestwick, C.S., Richardson, A.J., McKain, N., Larson, T.R., Graham, I.A. and Wallace, R.J. (2010) Toxicity of Unsaturated Fatty Acids to the Biohydrogenating Ruminal Bacterium, Butyrivibrio fibrisolvens. BMC Microbi- 
ology, 10, Article No. 52. https://doi.org/10.1186/1471-2180-10-52

[5] Toral, P.G., Hervás, G., Carreño, D., Leskinen, H., Belenguer, A., Shingfield, K.J., and Frutos, P. (2017) In Vitro Response to EPA, DPA, and DHA: Comparison of Effects on Ruminal Fermentation and Biohydrogenation of 18-Carbon Fatty Acids in Cows and Ewes. Journal of Dairy Science, 100, 6187-6198. https://doi.org/10.3168/jds.2017-12638

[6] Kristofersson, D. and Anderson, J.L. (2006) Is There a Relationship between Fisheries and Farming? Interdependence of Fisheries, Animal Production and Aquaculture. Marine Policy, 30, 721-725. https://doi.org/10.1016/j.marpol.2005.11.004

[7] Tacon, A.G.J., Hasan, M.R. and Subasinghe, R.P. (2006) Use of Fishery Resources as Feed Inputs to Aquaculture Development: Trends and Policy Implications.

[8] Martí, M., Ortiz, X., Gasser, R., Martí, M., Montaña, M.J. and Díaz-Ferrero, J. (2010) Persistent Organic Pollutants (PCDD/Fs, Dioxin-Like PCBs, Marker PCBs, and PBDEs) in Health Supplements on the Spanish Market. Chemosphere, 78, 1256-1262. https://doi.org/10.1016/j.chemosphere.2009.12.038

[9] Reijnders, P. and Simmonds, M. (2002) Global Temporal Trends of Organochlorines and Heavy Metals in Pinnipeds. In: Vos, J., Bossart, G., Fournier, M. and O'Shea, T., Eds., Toxicology of Marine Mammals, Taylor \& Francis, London, 247-269.

[10] Hong, M.Y., Lumibao, J., Mistry, P., Saleh, R. and Hoh, E. (2015) Fish Oil Contaminated with Persistent Organic Pollutants Reduces Antioxidant Capacity and Induces Oxidative Stress without Affecting Its Capacity to Lower Lipid Concentrations and Systemic Inflammation in Rats. The Journal of Nutrition, 145, 939-944. https://doi.org/10.3945/jn.114.206607

[11] Astiasarán, I. and Ansorena, D. (2009) 19-Algal Oils. AOCS Press, Urbana, 491-513. https://doi.org/10.1016/B978-1-893997-97-4.50025-5

[12] Winwood, R.J. (2015) 6-Algal Oils: Properties and Processing for Use in Foods and Supplements. In: Talbot, G., Ed., Specialty Oils and Fats in Food and Nutrition, Woodhead Publishing, UK, 159-172. https://doi.org/10.1016/B978-1-78242-376-8.00006-5

[13] Leyland, B., Leu, B.S. and Boussiba, S. (2017) Are Thraustochytrids Algae? Fungal Biology, 121, 835-840. https://doi.org/10.1016/j.funbio.2017.07.006

[14] Dillon, G.P., Keegan, J.D. and Moran, C.A. (2020) Toxicological Evaluation of an Unextracted Aurantiochytrium limacinum Biomass, a Novel Docosahexaenoic Acid Rich Feed Ingredient. Food and Chemical Toxicology, 141, Article ID: 111397. https://doi.org/10.1016/j.fct.2020.111397

[15] Moran, C.A., Morlacchini, M., Keegan, J.D. and Fusconi, G. (2018) The Effect of Dietary Supplementation with Aurantiochytrium limacinum on Lactating Dairy Cows in Terms of Animal Health, Productivity and Milk Composition. Journal of Animal Physiology and Animal Nutrition, 102, 576-590. https://doi.org/10.1111/jpn.12827

[16] Moran, M., Morlacchini, J.D. and Keegan, G. (2018) Fusconi, Dietary Supplementation of Finishing Pigs with the Docosahexaenoic Acid-Rich Microalgae, Aurantiochytrium limacinum: Effects on Performance, Carcass Characteristics and Tissue Fatty Acid Profile, Asian-Australasian. Journal of Animal Science, 31, 712-720. https://doi.org/10.5713/ajas.17.0662

[17] Moran, C.A., Currie, D., Keegan, J.D. and Knox, A. (2018) Tolerance of Broilers to Dietary Supplementation with High Levels of the DHA-Rich Microalga, Aurantiochytrium limacinum: Effects on Health and Productivity. Animals, 8, 180. https://doi.org/10.3390/ani8100180 
[18] Keegan, J.D., Currie, D., Knox, A. and Moran, C.A. (2019) Redressing the Balance: Including DHA-Rich Aurantiochytrium limacinum in Broiler Diets Increases tissue Omega-3 Fatty Acid Content and Lowers the N-6:N-3 Ratio. British Poultry Science, 60, 414-422. https://doi.org/10.1080/00071668.2019.1605153

[19] Moran, C.A., Morlacchini, M., Keegan, J.D. and Fusconi, G. (2019) Increasing the Omega-3 Content of Hen's Eggs Through Dietary Supplementation with Aurantiochytrium limacinum Microalgae: Effect of Inclusion Rate on the Temporal Pattern of Docosahexaenoic Acid Enrichment, Efficiency of Transfer, and Egg Characteristics. Journal of Applied Poultry Research, 28, 329-338.

https://doi.org/10.3382/japr/pfy075

[20] Keegan, J.D., Currie, D., Knox, A. and Moran, C.A. (2019) Heterotrophic Aurantiochytrium sp. Supplementation to layer Diets Sustainably Increases the Omega-3 Concentration of Eggs. British Poultry Science, 60, 570-578. https://doi.org/10.1080/00071668.2019.1622079

[21] Speight, N. (2012) Mycotoxin-Related Illness. Taylor \& Francis Group, Boca Raton, 821-850.

[22] Sasso, S., Pohnert, G., Lohr, M., Mittag, M. and Hertweck, C. (2012) Microalgae in the Postgenomic Era: A Blooming Reservoir for New Natural Products. FEMS Microbiology Reviews, 36, 761-785. https://doi.org/10.1111/j.1574-6976.2011.00304.x

[23] Hermosa, R., Cardoza, R.E., Rubio, M.B., Gutiérrez, S. and Monte, E. (2014) Chapter 10-Secondary Metabolism and Antimicrobial Metabolites of Trichoderma. In: Gupta, V.K., Schmoll, M., Herrera-Estrella, A., Upadhyay, R.S., Druzhinina, I. and Tuohy, M.G., Eds., Biotechnology and Biology of Trichoderma, Elsevier, Amsterdam, 125-137. https://doi.org/10.1016/B978-0-444-59576-8.00010-2

[24] El-Bondkly, A.M.A. (2014) Chapter 28-Sequence Analysis of Industrially Important Genes from Trichoderma. In: Gupta, V.K., Schmoll, M., Herrera-Estrella, A., Upadhyay, R.S., Druzhinina, I. and Tuohy, M.G., Eds., Biotechnology and Biology of Trichoderma, Elsevier, Amsterdam, 377-392. https://doi.org/10.1016/B978-0-444-59576-8.00028-X

[25] Cronan, J.E. and Thomas, J. (2009) Chapter 17 Bacterial Fatty Acid Synthesis and Its Relationships with Polyketide Synthetic Pathways. Methods in Enzymology, 459, 395-433. https://doi.org/10.1016/S0076-6879(09)04617-5

[26] Food and Drug Administration Center for Veterinary Medicine (CVM) (2016) Guidance for Industry \#3: General Principles for Evaluating the Human Food Safety of New Animal Drugs Used in Food-Producing Animals.

https://www.fda.gov/regulatory-information/search-fda-guidance-documents/cvmgfi-3-general-principles-evaluating-human-food-safety-new-animal-drugs-used-foo d-producing

[27] Food and Drug Administration Center for Veterinary Medicine (CVM) (2003) Guidance for Industry \#152: Guidance for Industry: Evaluating the Safety of Antimicrobial New Animal Drugs with Regard to Their Microbiological Effects on Bacteria of Human Health Concern. Federal Register, 68, Article ID: 61221.

https://www.fda.gov/regulatory-information/search-fda-guidance-documents/cvmgfi-152-evaluating-safety-antimicrobial-new-animal-drugs-regard-their-microbiolo gical-effects

[28] Food and Drug Administration Center for Veterinary Medicine (CVM) (2012) Guidance for Industry \#159: (VICH GL36) Studies to Evaluate the Safety of Residues of Veterinary Drugs in Human Food: General Approach to Establish a Microbiological ADI.

[29] AOAC International (2005) Official Methods of Analysis of AOAC International, 
Official Method 990.03. Gaithersburg, MD, USA.

[30] AOAC International (2005) Official Methods of Analysis of AOAC International, Official Method 954.02. Gaithersburg, MD, USA.

[31] AOAC International (2005) Official Methods of Analysis of AOAC International, Official Method 999.06. Gaithersburg, MD, USA.

[32] AOAC International (2005) Official Methods of Analysis of AOAC International, Official Method 930.15. Gaithersburg, MD, USA.

[33] AOAC International (2005) Official Methods of Analysis of AOAC International, Official Method 942.05. Gaithersburg, MD, USA.

[34] Blanc, G., Duncan, G., Agarkova, I., Borodovsky, M., Gurnon, J., Kuo, A., Lindquist, E., Lucas, S., Pangilinan, J., Polle, J., Salamov, A., Terry, A., Yamada, T., Dunigan, D.D., Grigoriev, I.V., Claverie, J.-M. and Van Etten, J.L. (2010) The Chlorella variabilis NC64A Genome Reveals Adaptation to Photosymbiosis, Coevolution with Viruses, and Cryptic Sex. The Plant Cell, 22, 2943-2955.

https://doi.org/10.1105/tpc.110.076406

[35] Manning, S.R. and La Claire, J.W. (2013) Isolation of Polyketides from Prymnesium parvum (Haptophyta) and their Detection by Liquid Chromatography/Mass Spectrometry Metabolic Fingerprint Analysis. Analytical Biochemistry, 442, 189-195. https://doi.org/10.1016/j.ab.2013.07.034

[36] (2015) National Committee for Clinical Laboratory Standards, M02-A12: Performance Standards for Antimicrobial Disk Susceptibility Tests; Approved Standard-Twelfth Edition. Clinical \& Laboratory Standards Institute, 35, 73.

[37] Cockerill, F.R., Wiker, M.A., Alder, J., Dudley, M.N., Eliopoulos, G.M., Ferraro, M. J., Hardy, D.J., Hecht, D.W., Hindler, J.A., Patel, J.B., Powell, M., Swenson, J.M., Thomson, R.B., Traczewski, M.M., Turnidge, J.D. and Weinstein, M.P. (2018) Methods for Dilution Antimicrobial Susceptibility Tests for Bacteria That Grow Aerobically.

[38] AOAC International (2005) Official Methods of Analysis of AOAC International, Official Method 985.01. Gaithersburg, MD, USA.

[39] AOAC International (2005) Official Methods of Analysis of AOAC International, Official Method 975.08. Gaithersburg, MD, USA.

[40] U.S. EPA (2014) Method 6020B (SW-846): Inductively Coupled Plsama-Mass Spectrometry. Washington DC.

[41] ASTM International (2011) ASTM D6722-11. ASTM International, Pennsylvania.

[42] U.S. FDA (2001) Bacteriological Analytical Manual, Chapter 3, Aerobic Plate Count.

[43] U.S. FDA (2002) Bacteriological Analytical Manual, Chapter 4, Enumeration of Escherichia coli and the Coliform Bacteria.

[44] U.S. FDA (2001) Bacteriological Analytical Manual, Chapter 12, Stapylococcus aureus.

[45] U.S. FDA (2001) Bacteriological Analytical Manual, Chapter 18, Yeasts, Moulds and Mycotoxins.

[46] Labbe, R.G. (2001) Chapter 33. Clostridium perfringens. In: Salfinger, Y. and Tortorello, M.L., Eds., Compendium of Methods for the Microbiological Examination of Foods, American Public Health Association, Washington DC.

[47] U.S. FDA (2016) Bacteriological Analytical Manual, Chapter 5, Salmonella.

[48] U.S. FDA (2016) Bacteriological Analytical Manual, Chapter 10, Detection and 
Enumeration of Listeria monocytogenes.

[49] (2005) Official Methods of Analysis of AOAC International, Official Method 965.33. AOAC International (Ed.), 18th Edition, Gaithersburg, MD.

[50] U.S. EPA (2007) Method 8081B.Organochlorine Pesticides by Gas Chromatography. Revision 2, Washington DC.

[51] Yokoyama, R. and Honda, D. (2007) Taxonomic Rearrangement of the Genus Schizochytrium Sensu Lato Based on Morphology, Chemotaxonomic Characteristics, and 18S rRNA Gene Phylogeny (Thraustochytriaceae, Labyrinthulomycetes): Emendation for Schizochytrium and Erection of Aurantiochytrium and Oblongichytrium gen. nov. Mycoscience, 48 199-211. https://doi.org/10.1007/S10267-006-0362-0

[52] Colombo, S.M., Campbell, L.G., Murphy, E.J., Martin, S.L. and Arts, M.T. (2018) Potential for Novel Production of Omega-3 Long-Chain Fatty Acids by Genetically Engineered Oilseed Plants to Alter Terrestrial Ecosystem Dynamics. Agricultural Systems, 164, 31-37. https://doi.org/10.1016/j.agsy.2018.03.004

[53] Shin, S.Y., Bajpai, V.K., Kim, H.R. and Kang, S.C. (2007) Antibacterial Activity of Bioconverted Eicosapentaenoic (EPA) and Docosahexaenoic Acid (DHA) Against Foodborne Pathogenic Bacteria. International Journal of Food Microbiology, 113, 233-236. https://doi.org/10.1016/j.ijfoodmicro.2006.05.020

[54] Choi, J.S., Park, N.H., Hwang, S.Y., Sohn, J.H., Kwak, I., Cho, K.K. and Choi, I.S (2013) The Antibacterial Activity of Various Saturated and Unsaturated Fatty Acids Against Several Oral Pathogens. Journal of Environmental Biology, 34, 673-676.

[55] Sun, M., Zhou, Z., Dong, J., Zhang, J., Xia, Y. and Shu, R. (2016) Antibacterial and Antibiofilm Activities of Docosahexaenoic Acid (DHA) and Eicosapentaenoic Acid (EPA) against Periodontopathic Bacteria. Microbial Pathogenesis, 99, 196-203. https://doi.org/10.1016/j.micpath.2016.08.025

[56] Sun, M., Dong, J., Xia, Y. and Shu, R. (2017) Antibacterial Activities of Docosahexaenoic Acid (DHA) and Eicosapentaenoic Acid (EPA) against Planktonic and Biofilm Growing Streptococcus mutans. Microbial Pathogenesis, 107, 212-218. https://doi.org/10.1016/j.micpath.2017.03.040 